\title{
Consumo Infantil de Alcohol en Dos Poblaciones Urbanas
}

\author{
Dra. Carmen Albornoz V.: ${ }^{1}$ Dra. Lidiz González L.; ${ }^{2}$ Nutr. Srta. Mónica Verdugo C.. ${ }^{3}$
}

\section{ALCOHOL CONSUMPTION IN CHILDREN}

\begin{abstract}
Sixty eight low income (Group A) and 65 middle income (Group B) families were investigated for alcohol consumption New borns and children less than two years of age constituted $59 \%$ of the Group A and $29 \% \%$ of the Group B families. Daily, weekly or bimonthly alcohol consumption ocurred in 51,5\% of Group A and $12,3 \%$ of Group B members. $71,1 \%$ of the families in Group A and 26,1\% in Group B offered alcohol to their children. The reason for this conduct are discussed and reflect the cultural level of the population under study; A combined educational health program is proposed, with emphasis on prevention of alcoholism in pregnant worren and the first decades of life.
\end{abstract}

El consumo excesivo de bebidas alcohólicas constituye uno de los principales problemas de Salud Pública en el País. Asi el $60^{\circ} / 0$ de la población mayor de 15 atios son bebedores moderados, el $15 \%$ excesivos y el $50 \%$ alcohólicos ${ }^{4}$.

Tan lamentables cifras están condicionadas por factores muy dificites de evaluar, pero la conducta de beber alcohol es cultural y socialmente aceptada, y está tan incorporada a nuestra idjosincracia que los padres no sólo asumen un papel permisivo hacia la ingestión de bebidas alcohólicas por parte de sus hijos, sino que, además, bajo distintas fomas, inducen al menor al consumo.

El niño es un receptor pasivo de costumbres, hábitos y creencias que sus progenitores van induciéndole, respaldados por todo el ambiente sociocultural en que están inmersos y que muchas veces terminan comprometiendo su crecimiento, desarrollo y perpetuando el hábito de beber en forma anomal, a través de distintas ge. neraciones.

En nuestro país, no sólo parece aumentar la demanda de bebidas alcohólicas, sino tambiền su disponibilidad por una producción alta $y$ un costo relativamente bajo, comparado con el de los alimentos esenciales para nuestra población infantil.

Debido a estos problemas se ha ido creando programas de apoyo para combatir el aicoholismo, tales como: la subvención de clubes de rehabilitación de alcohólicos, programas de prevención primaria en la Comunidad Escolar chilena, refuerzo en los estudios curriculares de las carreras de la Salud y Educación, entre otros.

1 Médico Pediatra del Hospital de La Unión

2 Médico Integral, Servicio de Pediatría Hospital de La Uniôn.

3 Nutricionista del Hospital de La Unión
El equipo de Salud del Servicio de Pediatría del Hospital "Dr. Juan Morey F." de La Unión, motivado por la inquietud de conocer los hábitos de ingesta de alcohol en los niños, decidió hacer el presente estudio en la comunidad urbana de nuestra ciudad.

\section{MATERIAL Y METODO}

Se tomaron dos poblaciones de la ciudad: La población A que incluyó los sectores Llollelhue, Ultra - Llollelhue y Mediaguas, considerado socioeconómicamente muy bajo, con un total de 68 familias, $y$ la población $B$ que correspondió a la población Radimadi, de nivel socioeconómico in. termedio con un total de 65 familias.

Se decidió hacer encuestas a través de visitas domiciliarias, entrevistando a dueñas de casa, a quienes se les preguntó:

- Actividad del dueño de casa.

- Tipo de alimentación que recibía la fanilia para situar en este contexto el consumo de alcohol.

- ¿Le da vino, chicha o malta con huevo a sus hijos, en las manaderas?

- Si contestaba afirmativamente, se le preguntaba edad de comienzo, cantidad y motivo por qué le daba.

- A continuación se les preguntaba si le daba vino, chicha o malta con huevo a los preescolares o escolares, edad de comienzo de la ingestión, cantidad y motivación para darle.

- Se preguntó consumo en los familiares que rodeaban al nifo. Este último parámetro fue eliminado pues en la entrevista directa a las madres pudo deducirse que habia sido falseado.

- El consumo de alcohol por los niños fue tomado como una sola unidad por familia y no en forma individual.

- La frecuencia de consumo de alcohol fue dividida en diaria, semanal, quincenal, mensual y ocasional (frecuencia mayor de 30 dias). 
Se compararon ambas poblaciones, calculando el significado estadistico de las diferencias en los resultados según test $Z$ para comparación de porcentajes.

\section{RESULTADOS}

Se encontraron importantes diferencias entre ambas poblaciones al considerar la ocupación del jefe del hogar. La población A tiene un nivel șocioeconómica muy bajo, no solamente por su tipo de actividad, que lleva implícito un menor ingreso, sino tambiér por aspectos como menor ca. lidad de la vivienda, mayor nụ́mero de hijos, menor calidad de la alimentación y mayor hacinamiento.

El tipo de actividad predominante en la población A (Tabla 1) fue el Plan de Empleo Mínimo con un 36,8 \% 0 versus 6,2 en Ja población $B$. La actividad màs frecuente en la población $B$ fue de empleado, con $33,8 \%$ no habiendo encontrado esta actividad en la población $\mathrm{A}$.

Tabla 1.

Tipo de actividades desarolladas en dos pablaciones de la ciudad de La Unión

(Encuesta hecha por el Equipo de Salud Aposto - Scptiembre de 1983)

Tipo de actividad

Población A Población B

\begin{tabular}{lcrrr} 
& $\begin{array}{c}\text { No } \\
\text { I.amilias }\end{array}$ & \multicolumn{4}{c}{$\begin{array}{c}N^{\circ} \\
\text { Viamilias }\end{array}$} & $\% / 0$ \\
Profesional & - & - & 1 & 1.6 \\
Empleado & - & - & 22 & 33.8 \\
Obrero & 22 & 32.3 & 8 & 12.3 \\
PEM & 25 & 36.8 & 4 & 6.2 \\
Ocasional & 3 & 4.4 & 3 & 4.6 \\
Cesarte & 18 & 26.5 & 6 & 9.2 \\
Jubilados SSS. & - & - & 8 & 12.3 \\
Pensionados & - & - & 13 & 20.0 \\
Total & 68 & 100.0 & 65 & 100.0
\end{tabular}

También habia diferencias notables en el nivel de cesantia, que para la población $A$ fue de $26,50 \%$ contra 9,2 en la población $B$.

En la población A, habia 49 familias $(72,1 \% \%)$ que daban a sus hijos bebidas alcohólicas (Tabla 2).

Tabla 2.

Ingestión de alcohol por los niños de dos poblaciones de la ciudad de La Unión

\begin{tabular}{lcrcr} 
Consumo de alcohol & \multicolumn{2}{c}{ Población A } & \multicolumn{2}{c}{ Población B } \\
& $\begin{array}{l}\text { No } \\
\text { Jamilias }\end{array}$ & \multicolumn{3}{c}{ No } \\
& & & Framilias & $0 \% 0$ \\
Consumen & 49 & 72.1 & 17 & 26.1 \\
No consumen & 19 & 27.9 & 48 & 73.9 \\
Total & 68 & 100.0 & 65 & 100.0
\end{tabular}

En la población B se escontró sólo 17 familias $(26,1 \%$ o) con igual comportamiento. La diferencia es significativa $(p=0,01)$.

En relación a la frecuencia con que se consume alcohol (Tabla 3), en la población B el $73,8 \%$ de las familias nunca han dado de beber a sus hijos comparado con un $27,9 \%$ de la población $A(p=0,01)$. También se observa que la población $A$, consume más frecuestemente alcohol, pues lo iracen cada 15 o menos día en una proporción de $51,5 \%$ lo que ocurre en sólo $12,3 \%$ de los casos en la población B.

Tabla 3.

Frecuencia con quc las Familias dan a beber alcohol a sus Hijos en dos poblaciones de La Unión

\begin{tabular}{lrrrr} 
& \multicolumn{2}{c}{$\begin{array}{c}\text { Población A } \\
\text { No } \\
\text { Familias }\end{array}$} & \multicolumn{3}{c}{$\begin{array}{c}\text { Población B } \\
\text { No } \\
\text { Familias }\end{array}$} & $\%$ \\
Nunca & 19 & 27.9 & 48 & 73.8 \\
Oedsional & $1]$ & 16.2 & 7 & 10.8 \\
Hensual & 3 & 4.4 & 2 & 3.1 \\
Quincenal & 11 & 16.2 &. & 0.0 \\
Semanal & 13 & 19.1 & 4 & 6.2 \\
Diătio & 11 & 16.2 & 4 & 6.1 \\
Total & 68 & 100.0 & 65 & 100.0
\end{tabular}

Al comparar la edad de comienzo del consumo de bebidas alcohólicas (Tabla 4), pudo comprobarse que en la población A se iniciaba más precozmente, con un $59,20 \%$ en lactantes $y$ recién nacidos, comparado con $29,40 / 0$ en las mis. mas edades de la población $B$.

Tabla 4.

Edad de comienzo del consumo de aicohol en los niños. Comparación de dos poblaciones de La Uniön

\begin{tabular}{cc} 
Población A & \multicolumn{2}{c}{ Población B } \\
No & No \\
Jamilias o/o & Iamilias $0 / 0$
\end{tabular}

Recién nacidos

Lactante

Prescolar

rscolar

Total

$\begin{array}{rrrr}1 & 2.1 & - & \\ 28 & 57.1 & 5 & 29.4 \\ 18 & 36.7 & 6 & 35.3 \\ 2 & 4.1 & 6 & 35.3 \\ 49 & 100.0 & 17 & 100.0\end{array}$

En el Grupo A se incluye un recién nacido al cual la abuela daba vino a las manaderas desde que salió de la maternidad.

Las motivaciones del adulto para ofrecer alcohol a los niños fueron expresadas de manera espontanea por las personas entrevistadas y reflejan el nivel cultural de esta población, ubicada dentro de una subcultura de ingestión excesiva y se muestra en la Tabla 5. 
Tabla 5 .

Motivo que lleva al adulto a ofrecer alcohol a los niños

\begin{tabular}{|c|c|}
\hline Población A & Potlación $\mathrm{B}$ \\
\hline $\begin{array}{ll}N^{0} & \\
\text { Jiamilias } & 0 / 0\end{array}$ & $\begin{array}{l}N^{\circ} \\
\text { IFamilias } \% / 0\end{array}$ \\
\hline
\end{tabular}

Para aumentar

galorías y energía

Para componer la

sangre

Porque al niño le

gusta

Para que acompañe a

los adulios

Total

\begin{tabular}{rrrr}
9 & 18.3 & 6 & 35.3 \\
4 & 8.2 & - & \multicolumn{1}{c}{-} \\
19 & 38.8 & 2 & 11.8 \\
17 & 34.7 & 9 & 52.9 \\
49 & 100.0 & 17 & 100.0
\end{tabular}

\section{CONCLUSIONES}

E1 consumo anormal de alcohol en nuestro país tiene una alta prevalencia. El $80 \%$ de ta población adulta aprendió este hábito en el seno de su propia familia ${ }^{4}$, lo que sugiere aspectos culturales negativos que nos obligan a reflexionar sobre los factores de riesgo en nuestra socjedad.

El hábito del consumo de alcohol es inversamente proporcional al nivel sacioeconómico de la población. Sumado a lo anterior, debemos tener presente que el consumo es mayor en cantidad y comienza en forma más precoz a medida que el nivel socioeconómico va descendiendo ${ }^{-2}$, lo que podría orientarnos para identificar los grupos de mayor riesgo y aplicar en ellos medidas educacionales tendientes a la corrección de tales hábitos.

Florenzano $y$ Cols. ${ }^{2}$ En un trabajo efectuado en cuatro Liceos de Santiago, encontró un consumo de $14,50 \%$ de alcohol en adolescentes. Hamame y Cols. ${ }^{3}$ encontraron una prevalencia de ingesta alcohólica de $84,1 \% / 0$ de los menores de 11 a 20 años que referían tener bebedores en su familia. Estos trabajos sumados al presente estudio, nos dan un panorama de la grave responsabilidad de los adultos en este problema.

Las motivaciones que llevan a los adultos a of recer alcohol a los menores son múltiples y reflejan una disposición cultural a la ingestión de afcohol por los nifios a pesar de la reticencia para reconocer el hábito alcohólico por los mismos adultos, que debemos suponer alto si los menores beben acompañando a los primeros.

Nos encontramos frente a un hecho real, que debe ser tratado en conjunto por los sectores de Salud y Educación mediante programas tendientes a la prevención del alcoholismo no solamente a partir de la época escolar, sino desde mucho antes, incluyendo las actividades de control nutricional de la embarazada, del nifo sano y la educación a través de las escuelas para padres.

Schuckit ${ }^{5}$ ha propuesto la interacción de fac. tores genéticos a cargo de dos tipos de genes opuestos en el alcoholismo, con factores ambientales predisponentes y protectores. Sobre estos últimos parámetros podemos actuar favoreciendo cambios positivos en los patrones culturales de nuestra población.

\section{RESUMEN}

Se encuestaron 68 familjas de la población A, de nivel socioeconómico muy bajo y 65 de la población $B$ de nivel intermedio.

Se encontró un $72,1 \%$ de consumo infantil de alcohol en la población $A$, comparado con un $26,10 \%$ de la población $\mathrm{B}$.

El consumo de alcohol diario, semanal y quincenal fué de $51,5 \%$ en la población A y de $12,40 \%$ en la población $B$.

Los recién nacidos y lactantes representaron un $52,2 \%$ en la pablación $A$ y $29,40 \%$ en la población $B$, lo que demuestra en la primera un consumo más precoz.

Se discutieron las mativaciones que llevaron al adulto a ofrecer alcohol a los niños lo que reflejaba un nivel cultural de la población.

Se propuso una acción educativa mixta Salud Educación, tendiente a incorpotar programas de prevención de alcoholismo en la embarazada y en etapas tempranas de la vida.

\section{BIBLIOGRAFIA}

1 Fernández, Anárés: "Investigación Sociológica y prevención primaria del Alcoholismo en Adolescentes". If Congreso Iberoamericano del alcohol $y$ alcoholismo. pp. 257-259, 1981 .

2 Florenzano, Ramón: "Características del grupo fami liar de adolescentes usuarios frecuentes de Alcohol, cigarrilio y marihuana, Santiago 1980". II Congreso fberoamericano de atcohol $y$ alcoholismo. pp. 154$158,198 \mathrm{I}$

3 Hamame, Alejandra: "Estudio de prevalencia de bebedores anormales en la División Salvador, CodelcoChile". II Congreso lberoamericano de alcohol $y$ alcoholismo. pp. 170-173,1981.

4 Medina. Eduarto: "Aspectos socioantropológicos del uso y abuso del alcohol". II Congreso Iberoamericano de alcohol y alcoholismo. pp. 19-25, 1981.

5 Sehuckit, M.A.: "A theory of alcohol and drug abuse A Genetic approach Na TI Int. Drug Abuse Res. Monog Ser 30, 297.302, 1980. 